\title{
O ENSINO DO TRABALHO SOCIAL NA EUROPA: O RECONHECIMENTO PELA UNIVERSIDADE EM QUESTÃO ${ }^{1}$
}

Emmanuel Jovelin ${ }^{2}$

\section{RESUMO}

Neste artigo, mostramos implicitamente, através do estudo do aparelho de formação em trabalho social nos países europeus, o desenvolvimento desta atividade e, sobretudo a diversidade que o caracteriza. Da mesma maneira que a prática profissional, a formação em trabalho social em nível europeu é múltipla. Assim, entre as escolas de formação, as escolas superiores e as universidades, diferentes tipos de ensino são realizados.

PALAVRAS-CHAVE: Universidade, Ensino, Trabalho Social, Europa.

Cada um dos países europeus apresenta uma organização específica do ensino do social. No entanto, a maior ou menor proximidade com a universidade permite reagrupamentos por país. Uma classificação que revela a importância atribuída à pesquisa e, conseqüentemente, os desafios do reconhecimento do trabalho social como disciplina.

O ensino do trabalho social na Europa está enraizado nas legislações e nos sistemas sociais diferentes segundo os países. Apresenta, no entanto certas estruturas similares que produzem diplomas mais ou menos idênticos. Os saberes fundamentais não difere muito, mas a variabilidade encontra-se em nível da duração, da organização e dos estágios. Em certos países europeus, o trabalho social é disciplina ensinada na universidade e vários deles preparam hoje em dia, doutorados em trabalho social. É o caso da Suécia, de Portugal, da Finlândia, do Reino Unido, da Hungria, da Alemanha,

\footnotetext{
${ }^{1}$ Artigo publicado na revista Informations Sociales, 2006/7, n 135, p. 120-129 (França) sob o título L'enseignement du travail social en Europe: la reconnaissance par l'université en question. Tradução de Edna Maria Goulart Joazeiro.

${ }^{2} \mathrm{O}$ autor é MCF em Sociologie, Diretor Adjunto de Recherches et Développement International Responsável pelo GERTS (Groupe d'Etudes et de Recherches en Travail Social) e dos Masters: Master 2 Travail Social en Europe e Master 2 Développement Social Urbain do Institut Social Lille Vauban/Université Catholique de Lille, France.
}

Revista Serviço Social \& Saúde. UNICAMP Campinas, v. VII-VIII, n. 7-8, Dez. 2009 
etc. Globalmente, existe uma quarentena de doutorados em trabalho social na Europa e mais de setenta nos Estados Unidos, sem esquecer os do Canadá ou da América Latina. Estas carreiras de doutorado são algumas vezes ligadas a quadros disciplinares clássicos existentes nas universidades, mas é um passo a frente para o reconhecimento do trabalho social como campo disciplinar.

\section{O ENSINO DO TRABALHO SOCIAL}

A formação dos trabalhadores sociais ocupa um lugar no sistema de ensino superior e o estatuto do ensino do trabalho social nos diversos sistemas nacionais de educação parece ser também um indicador do grau de profissionalização atingido pelos postulantes. $\mathrm{O}$ ensino do trabalho social entrou num processo secular de passagem do nível secundário ao nível superior de educação (Comité National des Écoles de Service Social, 1988). Na maior parte dos países, o ensino do trabalho social situa-se numa posição singular e paradoxal no interior do sistema do ensino superior, pelo fato de estar fora das universidades, mas se aproximando cada vez mais. Este ensino foi objeto de um reconhecimento pleno e inteiro por parte deste último na Islândia, na Irlanda, na Suécia, no Reino Unido, na Finlândia, na Itália, em Portugal, em Israel e também na Espanha. Em muitos países, os estudantes recebem uma qualificação geral que lhes dá oficialmente as competências necessárias para uma ampla gama de práticas do trabalho social. Contudo, foi o resultado de um longo e controverso processo que conduziu de uma especialização a uma generalização maior.

$\mathrm{Na}$ maioria dos países, a organização geral da formação dos trabalhadores sociais é da competência de um ministério (freqüentemente da Educação Nacional ou de Assuntos Sociais). O controle dos governos e seu compromisso para regulamentar a formação inicial do trabalho social tem variado em função nomeadamente do conteúdo das políticas sociais e da organização do Estado-Providência de cada país. Por exemplo, Revista Serviço Social \& Saúde. UNICAMP Campinas, v. VII-VIII, n. 7-8, Dez. 2009 
na Finlândia e na Suécia, a formação social é descentralizada, contudo este não é o caso no Reino Unido. Nos países europeus, houve enormes esforços para unificar os programas de formação de nível nacional. Assim, existe um programa nacional de formações iniciais nos países como a Bélgica, a República Checa, a França, a Grécia, a Itália, a Noruega, a Espanha, a Suíça e o Reino Unido. Mas alguns outros como a Dinamarca, a Estónia, a Finlândia, a Alemanha, a Eslováquia, a Eslovênia ou a Suécia dispõem de uma grande autonomia neste domínio. Somente alguns países como a Alemanha não tem uma direção centralizada do ensino do trabalho social, enquanto que uma forma mais centralizada de controle parece existir no Reino Unido, onde o NTO segue de maneira regular as exigências requeridas e o conteúdo das formações, assim como os diplomas e os títulos. Alguns países regulamentam o ensino do trabalho social de maneira legal (por exemplo, a Dinamarca, a Finlândia, a França ou a Espanha), enquanto em outros (a Áustria, a Bélgica, a Grécia, Luxemburgo, os Países Baixos, Portugal ou a Suécia) delegam ainda a responsabilidade do controle e a legislação ao Ministério da Educação, da Saúde ou a outros serviços específicos.

\section{OS PRINCIPAIS GRUPOS DE FORMAÇÃO DOS TRABALHADORES SOCIAIS NA EUROPA}

A formação dos trabalhadores sociais pode ser dividida em três grandes grupos que retomaremos abaixo, insistindo um pouco mais em alguns países que nos parecem característicos do conjunto no interior de grupos.

\section{NAS ESCOLAS E NOS ESTABELECIMENTOS ESPECÍFICOS}

O primeiro grupo compreende os países onde a formação inicial se realiza nos estabelecimentos extra-universitários (Áustria, Bélgica, Alemanha, Países Baixos, Suíça, etc.). Na Bélgica de língua francesa, por exemplo (FOUCART, 2008), a formação dos 
trabalhadores sociais por seu turno é essencialmente o ensino superior não-universitário de tipo curto, ou seja, um ciclo de três anos após o ensino secundário. As formações em regime de pleno exercício de assistente social e de educador especializado são asseguradas no âmbito das Escolas Superiores (hautes écoles). Quanto à Suíça, o trabalho social era um privilégio das escolas sociais. A partir dos anos 80, os diplomados universitários em ciências sociais começaram a fazer concorrência às escolas de serviço social. Mas estas últimas tiveram êxito em conservar e privilegiar os estudos orientados para a prática e a criar as exigências nos ramos teóricos. Então, naturalmente foram criadas as Escolas Superiores Especializadas (HES) (Hautes Écoles Spécialisées), consideradas "universités des métiers" ("universidades de ofícios"), equivalentes a universidades, mas também diferentes e complementares, a quem foram confiadas também à missão de desenvolver atividades de pesquisa aplicada.

No que concerne aos Países Baixos (BAILlERGEAU, 2008), no fim anos 80, importantes mutações ocorreram na formação profissional superior, e na dos trabalhadores sociais em particular, impulsionado pelo Ministério da Educação. Em 1989, uma operação geral de reorganização das formações superiores em trabalho social recompôs treze formações existentes em cinco novas, com um reagrupamento do conjunto dos ofícios de Animação e de Ação Social Comunitária: Cultureel en Maatschappelijk Vorming (formação cultural e social), de nível HBO. O ensino do trabalho social tem, por conseguinte lugar em escolas superiores independentes das universidades e que oferece, por sua vez, formações iniciais e contínuas no domínio do trabalho social, entre outros domínios de ensino. Os estudos sociais são, como em muitos outros domínios de estudo, divididos entre os estudos profissionais (NE)-HBO, realizados no Hogeschoolen, com número de vinte e duas, e os estudos pesquisa (mais teóricos) de (NE)-WO, realizados nas universidades. Não existe diploma nacional do 
trabalho social como na França, onde a formação é realizada nos centros de formação de estatuto associativo ou nos liceus públicos ou privados e nos institutos universitários.

O trabalho social na Alemanha distingue-se pelo seu sistema dual que compreende as instituições governamentais (o trabalho social público) bem como as organizações não-governamentais. São estes dois grupos que possuem o monopólio no setor. Existem escolas profissionais públicas ou privadas bem como institutos independentes e departamentos que fazem parte de institutos universitários (Fachhochschulen), para um ensino de três ou quatro anos de acordo com as regiões. A diferença do número de anos provém dos estágios, os departamentos do Sul preferem um estágio mais longo, contrariamente aos do Norte. Após a formação inicial, podem preparar um master em trabalho social. As instituições superiores alemãs tentam se adequar ao "processo de Bolonha", transpondo os antigos diplomas de bacharel "bachelor" (obtido após três anos) seguidas do master (após um ou dois anos de formação).

\section{A RELAÇÃO ENTRE UNIVERSIDADES E INSTITUTOS}

No segundo grande grupo, a formação inicial tem lugar ao mesmo tempo nas universidades e nos institutos extra-universitários (República Tcheca, Hungria, Polônia, Bulgária, Dinamarca, Grécia, Noruega, Suíça, França, etc.). Na Noruega, por exemplo, ainda que as formações em trabalho social tenham começado em 1920, em Oslo, elas não se situam na mesma linhagem que os outros países nórdicos como a Finlândia e a Suécia, onde elas são realizadas na universidade. Em 1967 foi criado um Conselho de Formação em Trabalho Social, e aproveitou-se para prolongar a duração da formação de dois anos e meio para três anos. Este último desenrola-se, por conseguinte, em três anos nos colégios não-filiados às universidades. Depois de alguns anos, existem programas 
de master em trabalho social, nomeadamente no Collège de Bodo e no de Oslo. Em 1985, além disso, foi instaurado um doutorado em trabalho social.

O modelo norueguês é quase idêntico ao da Dinamarca, onde a formação dos trabalhadores sociais tem duração de três anos e meio e se faz nos institutos de formação social. O caso da Suíça, mencionado acima, se junta a esse grupo, uma vez que conta com a cadeira de trabalho social da Universidade de Fribourg. Convém, além disso, não omitir a França, com os institutos universitários de tecnologia e as carreiras sociais, bem como o de Portugal, onde, até os anos oitenta, a formação em serviço social se fazia em três escolas privadas, no Porto, em Coimbra e em Lisboa. Estas escolas estavam sob a tutela do ministério, mas gozavam de certa autonomia. Hoje, há dois tipos de ensino distintos em trabalho social: o ensino superior universitário e o ensino superior politécnico. A formação dura quatro anos, e pode-se prosseguir até ao doutorado em serviço social. Por último, se na Bulgária a formação inicial foi reorganizada nos anos 70 e ensinada nas universidades públicas e privadas bem como nas escolas, pode-se acrescentar a esta categoria, entre outras, a República Checa e a Polônia.

\section{A UNIVERSIDADE NA PRIMEIRA LINHA}

O terceiro grande grupo compreende os países onde a formação inicial é essencialmente realizada na universidade (Estônia, Finlândia, Irlanda, Islândia, Itália, Romênia, Eslovênia, Espanha, Suécia, Reino Unido, Rússia, etc.). Na Itália, a reforma dos estudos universitários com a instauração dos cursos de especialização e de aperfeiçoamento aconteceu em 1982, mas é em 1987 que a formação dos assistentes sociais foi transferida para a universidade. A elevação do nível de educação obrigatório para os assistentes sociais marcou uma etapa no processo de profissionalização. Fora a profissão dos Assistentes Sociais, pode-se também citar a de Educador Profissional, Revista Serviço Social \& Saúde. UNICAMP Campinas, v. VII-VIII, n. 7-8, Dez. 2009 
que, após um período de cacofonia quanto ao nível requerido para o exercício profissional, integrou-se ao sistema universitário.

Hoje, esta formação é realizada nas Faculdades de Medicina pois estes trabalhadores sociais exercem nos setores médicos (junto a usuários de drogas, pacientes portadores de doenças mentais, crianças com dificuldades, etc.). Este diploma anteriormente era preparado em escolas de administração locais bem como nas faculdades de pedagogia, ainda hoje, os diplomas de animadores sociais são preparados desta forma. Existe, por conseguinte um diploma nacional do trabalho social como um primeiro nível obtido após três anos de formação, seguido de dois anos de especialização (master), antes de iniciar um doutorado para os estudantes que o desejarem. Hoje, a tendência na Itália é ter um ou três diplomas de trabalho social a fim de evitar a multiplicação das formações.

Para o Reino Unido, foi em 1971 que se instaurou o Conselho Central da Educação e a formação em trabalho social (CCETSW), que teve o poder de aprovar os ciclos de formação e que determinou o nível necessário para exercer a profissão de trabalhador social. Foi substituído, em 2003, pelo NTO, a Organização Nacional da Formação. Desde esta data, após um período de intensas consultas as formações dos trabalhadores sociais foram reformadas, com instauração de um diploma nacional nas universidades. Compete ao General Social Care Council (GSCC) acreditar, aprovar e avaliar a prática e as diferentes formações em trabalho social. Os novos diplomados são mais generalistas que os precedentes, tanto que na universidade, há um tronco comum com as parteiras, as enfermeiras e os trabalhadores sociais antes de se especializarem. Existe igualmente o doutorado em trabalho social.

Na Finlândia, a formação dos trabalhadores sociais, sobretudo desenvolveu-se nos anos 50, na Universidade de Helsinque, conjuntamente com as políticas sociais. O 
desenvolvimento do trabalho social como disciplina universitária ajudou à consolidação da pesquisa neste domínio. Atualmente, a formação em trabalho social é ensinada em seis universidades, reagrupadas em rede, que fornecem também ensino comum a distância. É construída sobre a idéia de qualificações universitárias necessárias em trabalho social, com uma duração média de cinco anos e meio. Por último, há duas espécies de instituições superiores: as universidades e as escolas politécnicas. As duas propõem uma formação as profissões sociais, mas só o diploma universitário é reconhecido como uma verdadeira qualificação neste domínio. A formação visa a assegurar o desenvolvimento da profissão e a reforçar a sua base científica trazendo avaliações teóricas e práticas. O objetivo é construir uma base de conhecimentos profissionais, de forma a prolongar o desenvolvimento do trabalho social como profissão fundada sobre a pesquisa. Esta abordagem é muito marginal no nível europeu. A Finlândia está adiantada em relação aos outros países europeus em matéria de pesquisa neste domínio, assim como a Suécia, onde o trabalho social é considerado igualmente como uma disciplina totalmente a parte, e onde se integrou ao sistema universitário desde 1977. Cinco universidades realizam o ensino desta disciplina, até o doutorado.

\section{O PROGRESSO DA ESPANHA}

Quanto à Espanha, a evolução do trabalho social (FEU, 2001) é caracterizado por um atraso na profissionalização na qual a Igreja católica desempenhou um papel, sobretudo nas primeiras fases do seu desenvolvimento. Será necessário esperar até o fim dos anos 50 e o início dos anos 60 para assistir a um começo do trabalho social, após um período de interrupção ligado a ditadura. O título de assistente social foi criado em

abril de 1964, por decreto do Ministério da Educação Nacional e das Ciências. O 
controle da formação pelo Estado tomará amplitude em 1967, com a criação, em Madrid, da única escola oficial de assistentes sociais.

Em 1980, graças ao impulso da Federação Espanhola das Associações das Assistentes Sociais, que apresentou um projeto de licença, o Parlamento aprovou a criação do título de diplomado em trabalho social e a transformação das escolas de assistentes sociais em escolas universitários de trabalho social. Portanto, a formação de trabalhadores sociais teve um salto qualitativo e quantitativo. A partir de 1983, o diploma em trabalho social foi integrado aos estudos de primeiro ciclo universitário de três anos de formação. Em 1990, com a criação das áreas de conhecimento de trabalho social e serviços sociais nas universidades, se assistiu a um reconhecimento importante do trabalho social como "disciplina", comportando a criação de ciclos universitários que permitem fazer avançar o ensino e a pesquisa. Desde os anos 1993-1994, a lei da reforma universitária permitiu uma renovação importante dos conteúdos, com projetos de formação mais flexíveis, adaptados a cada universidade.

\section{CONCLUSÃO}

De maneira geral, hoje, na Europa, a formação inicial tem a duração de três ou quatro anos, mas com o Acordo de Bolonha, várias instituições alinham-se sobre uma duração da formação de três anos. Assistimos, nestes últimos anos, à progressão da universitarização ["universitarisation"] da formação dos trabalhadores sociais, mas os programas de formação não diferem sensivelmente. Eles são compostos de três grandes elementos: os conhecimentos profissionais ou teóricos, as aptidões práticas, e por último, a aptidão para a pesquisa. No que concerne à prática, o tempo de estágio difere de um país para outro, e o mesmo se dá com a pesquisa, que é desenvolvida em função do lugar que se atribui ao campo de trabalho social no conglomerado das disciplinas científicas. Em vários países europeus, a pesquisa não faz parte das preocupações das Revista Serviço Social \& Saúde. UNICAMP Campinas, v. VII-VIII, n. 7-8, Dez. 2009 
instituições do trabalho social. Se nos países nórdicos, existe tal disposição, nos países em transição da Europa Central e Oriental, inicia-se agora esse interesse. Já que o trabalho social tinha sido completamente asfixiado durante o período comunista, era preciso começar a reorganizá-lo antes de se dedicar à pesquisa. Nos países da Europa Central e do Sul, a pesquisa existe no seio de algumas instituições, mas de forma esparsa, e não é integrada à formação, salvo talvez em países como a Suíça, a Grécia e, em menor escala, na Alemanha e no Reino Unido. Resumidamente, como mostra a diversidade no ensino nesse domínio, hoje, pode-se falar do Trabalho Social na Europa, mas não existe Trabalho Social Europeu no sentido próprio do termo, uma vez que as práticas profissionais diferem, em função do contexto local, regional e nacional de cada Estado (JOVELIN, 2008).

\begin{abstract}
In this article we implicitly show, through the study of the Social Work education at european countries, the development of this activity and, above all the diversity which distinguishes it. The same way as the profissional practice, the european Social Work education is multiple. Thus, among the training schools, the college and the universities, different kind of teaching are accomplished.
\end{abstract}

KEYWORD: University, Education, Social Work, Europe

\title{
REFERENCIAS BIBLIOGRAFICAS
}

BAILlERGEAU, E. Histoire du travail social au Pays-Bas. In: Jovelin, E.(éd), Histoire du travail social en Europe. Paris: Vuibert, 2008.

Comité National des Écoles de Service Social (CNESS). L'Action sociale et la formation des travailleurs sociaux en Europe: de l'étatisme au pouvoir des collectivités. Paris, 1988. 
FEU, M. L'évolution du travail social en Espagne. In: PRIEUR, E., JOVELIN,E. (éds.) Quel social pour quelle societé au XXIe Siècle? Paris, L'Harmattan, 2001 FOUCART, J. Histoire du travail social em Belgique. In: JOVELIN, E. (éd), Histoire du travail social en Europe. Paris: Vuibert, 2008.

JOVELIN, E. (ed.), Histoire du travail social en Europe, Paris: Vuibert, 2008. 290 p (Collection Perspectives Sociales) 
